\title{
NOW WHAT FOR THE WORLD'S BUSINESS SCHOOLS?
}

\author{
JAMES A. F. STONER \\ Gabelli School of Business \\ Fordham University \\ New York, New York, U.S.A. \\ stoner@fordham.edu
}

\section{THE CHALLENGE ("What's so?”)}

Our species faces the greatest challenge it has ever faced: how to transform the currently dominant global producing-distributingconsuming system from one that is destroying the planet's capacity to support our species into one that will enable our species and all others to continue to exist and "flourish forever" (in the words of John Ehrenfeld), "heal a broken world" (in the words of the Jesuit Task Force Report on Ecology), and achieve "integral ecology," "care for the vulnerable," and "care for our common home" (in the words and sub-title of Pope Francis's encyclical Laudato Si'). The system in which we live is clearly broken. It is continuously and increasingly damaging all aspects of the global ecosystem, creating almost unheard of levels of income and wealth inequality across the globe, bringing about climate change, global warming, and weather weirding that impact every area of the world, and marshaling in the sixth great extinction.

The challenge facing our species can seem particularly intractable because the ways we produce, distribute, and consume are embedded in a seemingly well-integrated, self-reinforcing, and powerful mechanism that is so well articulated and pervasive that it is hard to imagine even one possible alternative. And even if we can imagine many alternatives, the barriers to change seem so numerous and so impenetrable that we run the risk of disempowering ourselves and not even attempting to bring about changes that might look attractive and promising.

Nevertheless, while the very completeness and firmly interconnected nature of the global producing-distributing-consuming system present 
a seemingly impossible challenge, it is clear that the system cannot continue in its current form for very long. The planet's capacity to sustain it is fast being exhausted, and so it needs to be changed. One question, then, might be "how and when will it be changed?," although a better question might be "how can we intervene in the system to bring about change in directions that are desirable for our own and other species?"

From its inception, this Journal has been concerned with exploring how a more sustainable world can be sought and brought into being. Past, current, and future articles have been investigating and will continue to investigate ways in which any aspect of society can contribute to the necessary transformations in our habits of producing-distributingconsuming and ways of being in the world; in other words, how we can meet the greatest challenge facing our species. This issue of the Journal is no exception; it contains a number of articles that touch upon or address this challenge. These articles are introduced below, following a brief report on one initiative to embrace the challenge of global transformation.

\section{ONE RESPONSE TO THE CHALLENGE (“So what?”)}

The good news about such a seemingly monolithic, integrated, and all-encompassing system is that there are also a seemingly infinite number of places to intervene in it, places where it may be possible to start a positive transformation. One such place, which may be of special interest to readers of this journal, might be the domain of global business education, and one approach in this domain that might also be equally interesting is a 2016 initiative to transform business education into a vehicle for changing the global producing-distributingconsuming system, an initiative inspired by the MacArthur Foundation's 100\&Change competition.

On June 2, 2016, the MacArthur Foundation announced a $\$ 100$ million competition to solve a significant social problem. On July 10, the possibility of entering such a competition-with a proposal to transform business education into a vehicle for changing our global producing-distributing-consuming system-was briefly discussed at the $19^{\text {th }}$ Annual Meeting of the Colleagues in Jesuit Business Education (CJBE) at Le Moyne College in Syracuse, New York. Eight days later, in Nairobi, Kenya, the following resolution was unanimously passed at the $22^{\text {nd }}$ Annual World Forum of the International Association of Jesuit Business Schools (IAJBS): 
The annual meeting of the IAJBS requests the IAJBS leadership, CJBE leadership, and the rest of the network of Jesuit business schools to work together to apply for the MacArthur Foundation 100 million dollar $100 \&$ Change competition with a project to transform Jesuit business education to be fully aligned with the wisdom in Laudato Si', with our universally-valid Jesuit educational tenets, and with the need for global sustainability, social justice, and poverty alleviation.

On October 2, 2016, a proposal to utilize the network of Jesuit business schools as a vehicle for transforming not just Jesuit business education but all of business education and the world's producingdistributing-consuming system was submitted to the MacArthur Foundation. Unfortunately, it did not win the hundred million dollar prize, but its basic conceptual structure might still provide the germ of an idea for transforming both business education and our entire producingdistributing-consuming system.

The 2016 proposal accepts that global business education, to a very large extent, currently does what it is asked to do: train people to support, contribute to, and build their careers in the existing producingdistributing-consuming system in which we all live. But since that system is broken and cannot continue on its current trajectory, the proposal admits that current business teaching and research are actually contributing to the problem of global unsustainability rather than providing bold leadership for solving it.

The basic framework of the proposal also asserted that there is no single agreed upon model for reforming business teaching and research to become vehicles for transforming how we produce, distribute, and consume. Thus, building on Professor Hal Leavitt's observation that "when you don't know how to solve a problem, it's a good idea to give it to a group," the application proposed that the USD 100 million be invested across forty business schools that will each commit to transform its own curriculum in whatever way it chooses (or perhaps discovers), and to do so in the impossibly short period of only three years. This time frame was chosen partly because of the urgency of the global unsustainability problem and partly on the hypothesis that, in academe and elsewhere, what cannot be done in 20 years might well be possible to do in three.

The concept of the proposal, therefore, was not to train students who would, in 20,30, or 40 years, reach high enough positions in business and other organizations to be able to start bringing about the needed transformations in our producing-distributing-consuming system. Instead, the intent was to create a global conversation inspired by 40 
bold business schools seeking very, very visibly to do the impossible, a loud discussion that would get the immediate attention of global business, educational, governmental, and not-for-profit institutions around the world and, in doing so, begin the transformation of our producing-distributing-consuming system right now instead of decades down the road.

\section{NOW WHAT FOR THE WORLD'S BUSINESS SCHOOLS? (“Now what?")}

What we teach and research in business schools may well be a vehicle for influencing and changing how our world produces, distributes, and consumes. Another 100\&Change competition is scheduled for 2019 and another proposal similar to the one in 2016 might be submitted.

2019 is a long way off, however, and the global unsustainability problem seems to get worse every year. Moreover, business school teaching and research continue to support, to a large extent, our existing producing-distributing-consuming paradigm. As such, although it may be desirable to put together another application for the MacArthur Foundation to accomplish the same goal- the transformation of our total producing-distributing-consuming system-it might also be possible for business schools to take the lead in acting immediately without waiting until 2020 to see if such a grant will be awarded. One place to start might be with just one business school that is willing to admit that our global system is broken, that current business school education contributes to that brokenness, and that will show the way to healing that brokenness by transforming its own curriculum, perhaps in alignment with the Nairobi resolution, in the impossibly short time period of only three years and doing so in such a public way that the whole world will watch.

The question is: Is there such a business school somewhere that is willing to commit to doing the impossible in such an impossibly short period of time ... and are there, maybe, many other schools that can be inspired by the first school to do the same?

\section{THIS ISSUE OF THE JOURNAL}

Now to turn to the articles in this issue of the Journal.

In the second of three planned articles on transforming business education into a vehicle for changing our producing-distributing- 
consuming system, Frank Werner and James Stoner focus on the critical role our teaching and research in finance play in influencing the entire business school curriculum. In "Transforming Finance and Business Education: Finance's Unique Opportunities," they suggest that finance has an exceptional opportunity to play a leadership role in transforming the entire business curriculum. Moreover, while every finance faculty member and department can be a leader in transforming both finance and all of business education, they also describe why the finance faculty and departments in Jesuit business schools are particularly well-placed to do so.

In "Toward a Theory of the Arts and Sustainability," Nancy Bertaux and Kaleel Skeirik also directly address the opportunities to transform our producing-distributing-consuming system and our ways of being in the world. Recognizing the need to build "a wide base of public consensus for action" (p. 53) on the major changes we must undertake, they present a theoretical framework for the role the arts can play in creating that consensus. At the core of their perspective is their insight that the arts are very likely unique in their ability to speak to our hearts and souls, that artistic complexity can be a vehicle for matching the complexity of the challenges and changes we must deal with, and that this matching can inspire public engagement with the steps we need to take to achieve a sustainable world.

In "Sustainability Vision and Practice: The Apparent Gap Between Corporate Leaders' Pronouncements and the Perceptions of Polish and U.S. MBA Students from Three Universities," Al Rosenbloom and Douglas Ross explore an important aspect of the sustainability education that we provide in our MBA programs. They collected data from three different groups of MBA students and contrasted their perceptions of the training they were receiving with the skills and mindsets that corporate leaders indicated they would like their employees to have. While the students generally perceived a "positive link between sustainability practices and [the] performance" (p. 75) of business organizations, the authors' findings suggest that there were three gaps in student perceptions vis-à-vis the apparent needs of businesses:

between students wanting more in-depth study of sustainability versus the dearth of opportunities currently provided in their [MBA] programs (Gap 1); between students wanting engaged faculty members who are fully committed to teaching sustainability topics versus current in-class experiences of faculty perfunctorily presenting sustainability issues (Gap 2); and between students' normative understanding that sustainability improves corporate performance versus their assessment that their MBA 
programs are not fully developing the sustainability competencies needed to link performance outcomes with sustainability (Gap 3). (p. 92)

They also observe that Gap 3 "results in the students' perception that they are inadequately prepared to deal with workplace barriers that prevent sustainability from becoming a central, organizational concern" (p. 92). Rosenbloom and Ross then suggest ways these gaps can be closed.

In "Faith-Based Socially Responsible Enterprises: Selected Philippine Cases," Aliza Racelis focuses on the roles faith-based organizations are playing and can continue to play in contributing to a more sustainable world. She notes that particularly noteworthy is the success of faithbased social enterprises "in effecting sustainable and holistic change ... due to their rootedness in [and connectedness to] the community [thus being enabled to bridge socio-economic divides], the social capital they help produce, [the] respect they receive from the people," (p. 118) and an integrated approach to development and environment. Based on a review of the literature on faith-based social enterprises and her study of three Philippine ventures, she identifies the distinctive set of values of such organizations, their particular modes of operation and governance, and the unique places they hold within their communities and the larger society. She also provides a framework for predicting their success and contributions to a more sustainable world on the basis of two key factors: spiritual leadership and what she calls "Christian social capital."

Finally, Marinilka Kimbro and Eric Wehrly directly address one of the major sustainability-creating areas where we need innovation, transformative thinking, and transformative methods of analysis: capital allocation decisions involving projects with viable sustainability-related alternatives. In "Capital Planning, Selection, and Investment: Integrating Sustainability in Decision-Making," they detail major domains where existing capital investment analysis techniques and ways of thinking are mis-analyzing promising sustainability-contributing projects and often putting them at a disadvantage. The authors then go beyond pointing out the weaknesses of existing analytic techniques and thinking to provide concrete suggestions and processes for improving capital decisions that can contribute to a more sustainable world. Their article provides an excellent example of the kinds of new thinking that we must bring to the whole domain of transforming our producing-distributing-consuming system and ways of being in the world. 